\title{
Systematic and just: The use of a systematic review methodology in social work research
}

\author{
Emma Kelly
}

\begin{abstract}
This discussion paper is based on my experiences with the Social Care Institute for Excellence (SCIE) on a 12 day placement as part of the Research Development Initiative 4 (RDI4) program. Claims and counter claims are made about the appropriateness of a systematic review methodology in social work. These debates pivot around understandings of knowledge creation, function and ownership in social work and what constitutes evidence. This paper considers the contribution systematic review methodology can make to social work research. The SCIE systematic review is considered within the context of broader review types such as literature and narrative reviews. The review methodology developed by SCIE is promoted because of its explicit inclusion of service user and carer evidence. Systematic review methodology also offers social work researchers the opportunity to scrutinise their searching technique and process. A detailed examination of some obstacles in searching highlights the potential for error and bias. Frequently these are introduced unintentionally through a less than rigorous search of literature. It is hoped that an awareness of the pitfalls of literature searching will lead to greater transparency about claims made based on 'available knowledge'. Social work has a specific contribution to make to the systematic review methodology as we pioneer ways of including service users and carer experience and knowledge. Systematic reviews are an appropriate methodology for social work and present an opportunity for the profession to raise the profile of alternative but reliable sources of evidence.
\end{abstract}

Keywords: systematic review; knowledge; database searching; social work methodology; literature review

1. Lecturer in Social Work (Safeguarding Children) University of Salford

Address for correspondence: C.E.Kelly@salford.ac.uk

Date of publication (online): 20th September 2012 


\section{Introduction}

Systematic reviews occupy an important but under examined place in social work research. The aim of this paper is twofold. First, to consider the methodology of systematic reviews in social work research. Second, to examine the technical aspects of literature searching, which can affect outcome by introducing bias (McDonald, 2003). Underpinning this discussion is a focus on 'comprehensiveness', sources of knowledge and quality of evidence, which are the defining features of systematic reviews. A comprehensive coverage of published, unpublished and service user material should provide an overview of knowledge in an area. Each step of the journey of a systematic review is fraught with potential to 'miss' available information (McDonald, 2003). This may be a result of technical difficulties in access, database usage and coverage of material but also relates to the selection and production of a body of knowledge by a discipline (McDonald 2003; Taylor, Demspter \& Donnelly 2003; Rutter et al., 2011). Underpinning review methodology is the question 'how extensive is 'reasonable' for searching? (Taylor, 2009, p. 366).

As a developing academic discipline, social work researchers must be clear about the methodological approaches used and their influence on knowledge production. Approaches adopted 'should be congruent with the aims of values of social work practice' (Butler, 2002, p.245). It has been argued that the purposeful inclusion of social work values in social work research is one of its distinguishing features (Shaw et al., 2006). Whilst the emphasis placed on values varies there is a demonstrable professional commitment to social justice as defined in the BASW Code of Ethics (2012). This code highlights the need for social work to be committed to actively challenging power and resource differentials and these principles need to be applied to social work research methodology too. To date, the focus of social work research in the UK is principally on qualitative methodologies and how such approaches can capture underrepresented voices (for example Humphries, 2008). It is argued that systematic reviews also require us to be mindful of different forms of evidence because researchers must be vigilant to process. This need for vigilance should lead to questions about what sources are being used, encouraging transparency in defining what is 'known' (Taylor et al., 2003; Braye \& Preston-Shoot, 2007).

\section{Reviews \& systematic reviews}

\section{Review types}

Literature reviews are a standard part of many social work papers and research endeavours. Nearly all social work research will commence with a contextualisation of the study in relation to previously published literature (Grayson and Gomersall, 
2003). There are many variations on types of reviews including "literature reviews, scoping studies, briefing papers and rapid reviews' (Boaz, Ashby and Young, 2002, p.3). Grant and Booth (2009) from the discipline of librarianship suggest that there are at least 14 different types of review, each one with their own strengths and weaknesses. In essence, review designs differ in their comprehensiveness and treatment or 'synthesis' of study findings. A literature review can be a quick search in relevant journals to ascertain 'new' information to be incorporated into the researchers existing body of knowledge. The potential to miss relevant research is inherent with this approach. It can also indicate inadequate efforts to identifying relevant literature (McDonald, 2003) or demonstrate bias through a selective approach (Grayson and Gomersall , 2003). Other researchers will take a more planned approach to the collection of literature but will be beset with technical and methodological issues, some of which will be explored in the second half of this paper.

Identifying a literature review as 'systematic' is an indicator of rigour and replicability. The term systematic review indicates that the review has been undertaken against a set of standards (Boaz et al., 2002). The standards include developing a research protocol, specificity of the question being explored, identifying all relevant literature, examining the quality of the literature found, synthesising the results, removing bias and being mindful of new literature and the need to update the review (Rutter et al., 2011). Within these standards there is scope for interpretation and as a result there are some variations in how systematic a systematic review can be. In evidence based healthcare studies, the apex for a systematic review is the methodology prescribed in the Cochrane Handbook (2011) for review and dissemination. Utilising systematic review methodology a reviewer:

....attempts to collate all empirical evidence that fits pre-specified eligibility criteria in order to answer a specific research question. It uses explicit, systematic methods that are selected with a view to minimizing bias, thus providing more reliable findings from which conclusions can be drawn and decisions made (Higgins and Green, 2011,

Section 1.2.2)

Cochrane reviews are primarily associated with health-care studies and the international equivalent for social care (as well as education, crime and justice) is the review process established by the Campbell Collaboration. In addition to the explicit search and synthesis of studies a Campbell systematic review also requires a search for unpublished research 'to avoid publication bias' (Campbell Collaboration, 2011). Littel (2010) argues that there are few substantive differences between the two review methods; the main difference being the debate over whether to forefront 'reliable evidence' over best available evidence. This debate is critical to social work methodology too, yet such scrutiny and analysis of the acquisition of sources of knowledge are rarely transparent in social work literature reviews. 


\section{SCIE Systematic Reviews}

As a leading social care research organisation in England and Wales (the equivalent in Scotland is the Institute for Research and Innovation in Social Science, or IRISS), SCIE have established a set of guidelines for systematic reviews (Rutter et al., 2011). These guidelines are underpinned by guidance on knowledge creation and knowledge use in social care (Pawson, et al., 2003; Walter et al., 2004; Marsh \& Fisher, 2005). The systematic review is of primary importance at SCIE, a position based on their stated belief that 'systematic review methods can be applied to any type of question' (Rutter, et al., 2011, p 12). Two key aspects of the SCIE systematic review guidance are of particular significance and merit further exploration; the definition of the term systematic and the emphasis placed on inclusion of service users views. In the SCIE guidance the term research review and systematic review are used interchangeably. The definition offered for a systematic review is a literature search that uses a 'transparent, rigorous and comprehensive methodology' (Rutter et al., 2011, p 14). A particular emphasis is placed on replicability, so that the parameters of the literature search must be transparent to enable another set of researchers to replicate the literature search and by default, come up with the same findings. Rigorous refers to the measures put in place to ensure that all available studies are identified and located; a task that is becoming increasingly challenging with the explosion in published journal articles (Taylor et al., 2003).

The second key strand of a SCIE systematic review is the need to involve service users to ensure that service user knowledge is taken into account. SCIE in particular take a firm position on evidence and insist on the inclusion of service user views (Rutter, 2009; Rutter et al., 2011). This is a specific contribution that social work can make to the development of systematic review methodology, by developing mechanisms for the inclusion of service user views and 'knowledge' (Braye \& PrestonShoot, 2007; Rutter et al., 2011). According to SCIE, service users can be involved in numerous ways including scoping the review, working as part of the review team, as an advisory group to the study or identifying research that is about service user views (Rutter et al., 2011). The process of enabling service user participation and knowledge dissemination is not straightforward. Obstacles such as length of time required, expenses and commitment were all highlighted when service user participation was sought in relation to social workers application of the law (Braye $\&$ Preston-Shoot, 2005). Inclusion can lead to unexpected insights by:

...forcing the researchers and other stakeholders to scrutinize their assumptions. Such participation fundamentally challenges the established power relations in production and application of knowledge, thus acting as a key mechanism for anti-oppressive practice. (Braye \& Preston-Shoot, 2007, p.325)

This sharing, verifying and challenging of interpretation represents a fundamental 
shift in ways of establishing what is evidence in social work research and provides a template for more inclusive forms of review.

\section{Current situation in UK}

There are limited numbers of systematic reviews of social work in the UK (Marsh \& Fisher, 2004; Rutter et al., 2011) although since 2010 more have been published (for example, Webb and Carpenter, 2010: Woods et al., 2011). This increase mirrors a general rise in the number of systematic reviews across disciplines (Grant \& Booth, 2009) reflecting a policy-driven preoccupation with evidence based practice. There has also been an institutional effort to raise the profile of systematic reviews in social work research (McDonald 2003; Rutter et al., 2011) with the work of SCIE, the Campbell Collaboration social welfare group and the European Social Research Council (ESRC)-supported 'Systematic reviews in Social Policy and Social Care Centre' at the University of York. The low profile of systematic reviews in British social work can be in part attributed to the many challenges facing social work researchers. These include no dedicated public body to fund social work specific research, lack of overall government funding for social work research and the relatively recent recognition (2004) of social work as an academic discipline in its own right by the ESRC (Marsh $\&$ Fisher, 2005). Orme and Powell (2007, p989) comment on the need for a social work research strategy whilst acknowledging the complexity of this aim; as the strategy ' has to address the way research is produced and utilized, and acknowledge multiple stakeholders involved in the research process'. Furthermore, the relatively modest results in the 2003 RAE (Research Assessment Exercise) have resulted in low levels of ESRC funding for social work research (Orme and Powell, 2007).

Systematic reviews are often viewed with suspicion (Boaz et al., 2002) by social work researchers. Principally, this may be a result of the association between systematic reviews and the 'positivist' paradigm. The combination of the traditional value placed on a hierarchy of evidence and 'the explicit assumption that only certain types of knowledge are "real" hinders the uptake of systematic reviews in social work (Norton, 2008, p.382). Another challenge in promoting systematic reviews for social work research in the UK is the association with evidence based practice. For instance, part of ESRC program to improve social care knowledge production, led to the establishment of the Kings College London Evidence Network in 2001. The forefronting of 'evidence' takes us to the centre of the debate about the benefits and challenges of evidence based social work research, as the network aims to provide (rigorous) information to assist in 'better quality decision' making in social and public policy. As Boaz et al., (2002) points out a key feature of evidence based practice in healthcare is the findings of systematic reviews, leading the latter to become indelibly associated with the former. Questions are rightly asked about the transferability of this model to a social work context however, it may be that social work can add something to the development 
of the systematic review methodology (Boaz et al., 2002; Braye \& Preston-Shoot, 2005; Braye \& Preston-Shoot, 2007). Rather than reject it outright, the challenge is to develop the methodology of a systematic review so that it retains its key quality of rigour and reliability but is more open to different forms of evidence.

Both Cochrane and Campbell systematic review methodology allow for the inclusion of qualitative studies as long as they meet certain criteria. Systematic reviews in social work need to take a new approach to defining quality but in way that acknowledges that a triad of social justice, judgements of quality and judgments about method (Norton, 2008). The criteria are clear for quantitative studies yet it may be that most social care systematic reviews adopt a less rigorous approach to analysis of qualitative research (Grayson \& Gomersall, 2003). Determining quality in qualitative studies is a complex topic; numerous tools exist to assist e.g. Critical Skills Appraisal Skills Programme (CASP) and the Cabinet Office framework (Spencer et al., 2003). Rutter et al., (2011) emphasises that systematic does not mean that certain types of studies are excluded; it is the search that is systematic not necessarily the studies searched for. There is an emphasis of knowing what methods are used in studies so that the methodology must be made explicit for the reviewer to be able to evaluate the quality of the study, removing the 'epistemological hierarchy from the systematic review method' (Norton, 2008, p.384). To further remove bias in assessing the quality of each piece of evidence it is recommended that the literature identified is 'quality assured' by another person. The Campbell Collaboration are explicit on this matter; systematic reviews cannot be undertaken on one's own.

Traditional synthesis in systematic reviews requires meta-analysis of the studies identified however it is argued that this model does not easily lend itself to qualitative social work research (McDonald, 2003; Littel 2010). Qualitative studies present challenges as some are long, complicated projects that have multiple decision points which can affect outcome (Pawson 2002; Boaz et al., 2002). Such studies question how and at what point is difference or change achieved. SCIE's approach to synthesis depends on the type of studies that have been identified but emphasis is placed on 'an assessment of the strength of evidence contributed by a particular study in its own terms' (Rutter, et al., 2011, p.58). Pawson (2002) argues that given the contextual complexity of many interventions that a range of sources need to be included for analysis of evidence including fragmentary sources:

My methodological gold standard has thus been the rather unusual one of whether the fragment of evidence (and not the whole study) is 'fit for purpose'. The working rule is thus - does this piece of information constitute useful evidence to refine that portion of the theory under test? Such a methodological approach rests on the extremely high probability (in this case well founded) that no one report on a complex intervention can be comprehensive and cover its every aspect equally well. Pawson 2002, p.52.

Pawson (2002) applies this model to a systematic review of Megan's Law in the 
USA and in doing so makes claim for the role of inference in our analysis; this is perhaps been a default position for many although Pawson (2002) is amongst the first to acknowledge it as a methodological approach.

\section{What can systematic reviews offer?}

The strengths of a systematic review are many. They can reveal significant trends and practice implications through the synthesis of all available research in a given area, as well as identifying areas that need further research (Boaz et al., 2002). This synthesis of information can be used to determine policy developments ensuring that public money is invested in interventions that 'work'. Therefore at their best systematic reviews may actually 'legitimise action' (Braye \& Preston Shoot, 2007, p.331). Establishing what is known and not known in social work is a core part of developing a knowledge base for the profession and many agree that such a canon of knowledge is required (Taylor et al., 2003; Holden et al., 2009; Hodge, Lacasse \& Benson, 2011). According to Holden et al., (2007, p.487) 'the adequate identification and acquisition of the population of prior publications serves many purposes, but the most obvious is that research programs and theory development depend on a progressive (if not always orderly) path of dissemination and testing'. If searching is not done rigorously and with a mind to a range of evidence then the foundation of knowledge is flawed. Boaz et al., (2002) suggest that the principles of systematic reviews may have a positive impact on qualitative research because of the emphasis on clarity and transparency; this could lead to better 'standards for assessing the quality of qualitative research' (p.12).

\section{Searching bibliographic databases}

\section{Range of databases}

Bibliographic databases are constructed to enable both quick and advanced searches across a significant amount of literature; however there are a number of issues to be considered in working towards 'exhaustive' coverage (Clapton, 2010). A common approach to a literature review would involve searching databases for key terms, then following up these references and possibly finding further material through the reference lists of the articles identified (Hart, 2001). Unlike many other practice and academic disciplines, social work does not have its own reference database (Taylor 2003; Clapton, 2010; Hodge et al., 2011), so searches must be conducted across a number of databases allied to a range of professions. Social Care Online, managed by SCIE, is attempting to fill this gap but Taylor (2009) argues that its coverage is not 
sufficiently comprehensive for this purpose. According to Coren \& Marsh (2006), at least 20 named databases could be searched in relation to social care topics although this may not be necessary depending on the subject matter (Clapton, 2010). Some UK databases offer national coverage (for example, Ageinfo, ChildData) whilst others provide international coverage; according to McDonald (2003) a systematic review has to be international in its coverage of the literature. The practice of accessing the reference databases available at one's academic institution or place of research is acceptable only if this limitation is acknowledged in the methodology.

\section{Database construction}

There is a dearth of social work literature about the function and operation of bibliographic databases. Questions need to be addressed regarding the construction of databases, including who is paid for the task of data-inputting as well as the ethics and investment principles of the companies who provide databases (Holden et al., 2009). Database construction is not a neutral and objective activity. Mackay (2007) considers that databases present a restricted and socially constructed version of acceptable knowledge; 'because electronic reference databases searches reveal dominant social work discourses as mediated by information technology, the searches thus generated construct and confine the range of literature available' (Mackay, 2007,p237). Little social work research has been undertaken that considers which and what research is prioritised for inclusion in databases. Holden and colleagues have twice found that there is a substantial bias in the inclusion of some journal articles over others in the American database, Social Work Abstracts, hereafter SWA (Holden et al., 2007; Holden et al., 2009). Coverage of articles from 33 'core' social works journals (including British titles) were examined over a period of seven years (1989-1996) in SWA. Given that SWA claims to cover these 33 journals comprehensively Holden and colleagues were surprised to find a low coverage rate. Editions were missing from 27 of the 33 journals that SWA claimed to cover in full (Holden et al., 2009). In addition, they found bias in favour of SWA abstracting journal issues from the National Association of Social Workers; the largest professional body of social workers in the world, based in the US. Results such as these indicate the degree of caution required when using bibliographic databases; despite their intentions, they cannot be comprehensive. To rely on the databases to cover core social work journals will lead to potentially relevant articles being missed (Holden et al., 2009).

\section{Functionality}

In 2009, Taylor and colleagues examined the functionality of seven databases in relation to a chosen social work research question. They concluded that Medline, 
SSCI or the Social Sciences Citation Index and CINHAL (Cumulative Index to Nursing and Allied Health Literature) produced the most accurate 'hits' (relevant articles) although other specific databases (e.g. Ageinfo) would also be useful depending on the service user grouping (Taylor et al., 2009). Clapton (2010) highlights that database relevance varies depending on your chosen search topic; consequently reviewers should not stick to their favourite or default bibliographic databases. The possibility of substantial gaps in the information contained within databases and that these gaps might be unexpected is an important aspect in the review process. Checking two or more databases does not guarantee comprehensiveness either as each one may have partial coverage. Clapton (2010) found that whilst overlap exists between databases, 38\% of references for the chosen subject (children's social care) area were found in one database only. Other challenges include potential publication bias (Braye \& Preston-Shoot, (2007). This can lead to the prioritization of some articles over others, such as those that have positive results and 'because research with interesting, welcome or significant results is more likely to be published' (Braye $\&$ Preston Shoot, 2007, p.318). Research that has a negative or inconclusive result may be less attractive for publication, even though such findings may demonstrate that which is already 'instinctively' known in practice. Unintentional bias on the part of editors can also lead to some research remaining unpublished and hidden, which skews the social work knowledge base.

There has been an increase in the amount of social work research that is published (Taylor et al., 2003) creating a welcome but challenging field when searching. Hodge et al., (2011) identified a concomitant rise in the number of social work journals, from ten in 1978 to over 70 in 2005 . Unfortunately no published studies indicate whether the number of social work journals has increased or decreased since 2005. According to Hodge et al., (2011, p.2) the function of these journals is 'transmitting the field's intellectual ideals, concepts and accomplishments'. However, academic journals are only one source of information and present a range of issues for those who cannot pay or do not have institutional access. University information repositories, free online journals and blog based research present new means of information sharing and by implication for searching too. 'Open content' points to new horizons for literature dissemination and searching for academics, practitioners and service users and carers. Making literature and research available in more democratic domains highlight the current industry around paying for 'knowledge', which serves to limit access.

\section{Key words and indexing}

Database interfaces add another layer of complexity to the search process. User interfaces are what we are presented with when we look at a database; a set of graphics that make it easier to navigate our way around the actual database. Younger and Boddy (2008) conducted a simple health related search in one database across three interfaces 
to examine what if any discrepancies emerged. They found that it would be easy as a novice searcher to miss up to $70 \%$ of citations (Younger \& Boddy, 2008). Whilst they do not define a novice researcher, one assumes this to mean anyone who has not had specific training in complex database searching. To find the same citations across the three interfaces the researchers had to use a range of more sophisticated searching techniques such as truncation and amending the search terms. Successful searching requires an understanding of how each database operates; does it use index terms, what are the default options and what is the capacity of the database to manage complex search terms? A search that returns nil results may reflect the user's lack of knowledge of the intricacies of the database rather than no research. Very few social work researchers are offered this degree of training in how to maximise database searching so by default their results are problematic and even information specialists acknowledge the scale of the problem in social care (Clapton, 2010).

The role of key words and terms is pivotal to successful searching. Key words are what you search for in a particular database to find the available literature. There are a number of difficulties with key words. First, information specialists with social work specific knowledge need to take on the task of allocating appropriate search terms to the articles they input. Second, there is no national or internationally agreed set of key terms or 'controlled language' in social work databases (Clapton, 2010). Consequently the researcher needs to use multiple key words or different spellings of the same term to be certain that all available information has been retrieved. Different databases may require different search terms even though they may lead to the retrieval of identical articles (known as overlap). One hint is to check how the database functions in relation to key terms; are they 'natural' or is there a controlled index (which means that the indexer has pre-selected the search vocabulary). Search terms have to be adapted and amended as you progress with precise recording of all the combinations used so that someone else could replicate the search. Further development within social work research is needed to create a 'shared language.... around key word classification' (Braye and Preston-Shoot, 2007, p.318) and 'appropriate index terms and search filters' (Taylor 2009, p.367). This would be easier if social work had its own subject specific bibliographic database too.

\section{Other search strategies}

Recently Internet search engines have been found to offer valid alternatives to finding research literature. Hodge et al., (2011) argues that social work researchers may be as well to use Google Scholar as their primary search engine, a search strategy which is well-established in other disciplines. Through analysis of popular social work citations, it appears that 'Google Scholar appears to offer greater access to relevant, citeable content in the social sciences relative to Thomson ISI' (Hodge et al., 2011 p.4). Citations refer to the number of articles that refer/cite a particular article and 
as such the most popular reflect something about the knowledge base in social work. Analyzing 79 journals Hodge et al., (2011) found that two thirds of the most frequently cited articles appear in four journals, of which, incidentally, only one is British, namely The British Journal of Social Work. Information specialists would advise that Google Scholar is used in addition to bibliographic database searching as relying on the former alone is not a comprehensive search strategy (Clapton, 2010; Rutter et al., 2011).

Other search strategies include finding all the work by a published author and checking their reference lists (known as 'snowballing') or hand searching key journals, a process known as 'reference- harvesting'. Taylor et al., (2003) argue that databases must be used and hand-searching techniques cannot be relied on alone. The alternative is to consider whether electronic searches are themselves sufficient. One influential health-led study considered this question and explored the results that could be obtained through the above named methods of literature searching. 495 references were identified but only a quarter of which were found in the electronic search, which is quantified as 'an average of one useful paper [for] every 40 minutes of searching' (Greenhalgh and Peacock 2005, p.1065). Other papers, those not identified in an electronic search, were found through contacting colleagues (23\% of total papers). Reference-harvesting, was also useful as it led to a further 24 new studies being found however it is labour intensive given that the authors estimate it took on average nine hours searching for one successful 'hit'. Using a 'protocol-driven strategy' is not sufficient to guarantee 'comprehensiveness' however considerable time is required to ensure that important sources are not missed (Greenhalgh and Peacock 2005). Braye and Preston-Shoot (2007) concur and conclude that one cannot rely on database searching alone in social work research, as the knowledge area is underdeveloped.

\section{Grey literature}

Whilst Government reports are easily available in the UK, other literature may reside in specific databases, such as 'Sigle' and Open Grey (both European), which attempt to capture what is known as 'grey literature'. Grey literature includes PhD theses, conference reports, technical information, online resources and other documents that are not formally published and is the domain of much social work research (Clapton, 2010). A considerable amount of social work research remains unpublished, particularly that carried out by practitioners, creating real difficulties in ensuring all available material has been located. Explanations for this poor publication profile include the small scale nature of the research, that is has a local focus and that those doing the research, especially social work practitioners and service users and carers may not have the confidence to believe they can be published (Mitchell, Lunt \& Shaw, 2010). Little social work research has been done to consider the coverage of grey 
literature databases of social work research. Clapton (2010) concludes in her study on the coverage of children's social care topics across 16 databases that it was difficult to identify how much grey literature was being included in each databases. Anecdotally, Braye and Preston Shoot (2007) indicate a contradictory coverage; searching in grey literature they found articles that they were unaware of and yet were surprised at some of the gaps. Gaps cause concern as they indicate missing information, which in turn affects the reliability of the claims made in a literature review.

\section{Conclusion}

This paper considers the role of systematic reviews in social work research methodology. Three models for systematic review were identified with a focus on the approach developed by SCIE (Rutter et al., 2011). Systematic review methodology sits at one end of a spectrum of review types, many of which are currently used in British social work research such as the literature review. Undertaking a systematic review creates an opportunity for British social work researchers to contribute to the development of the methodology. Rather than rejecting systematic reviews because of their association with hierarchies of evidence, we have an opportunity to develop new ways of appraising 'quality' from a broad range of sources. The continued polarization of quantitative and qualitative methodologies is stifling a more interesting debate about how social work researchers can develop methods that reliably capture the complexities of the social world in which we practice and research. The contribution of service users and carers in the creation of knowledge for systematic reviews offers an opportunity for us all to shape the debate about what constitutes reliable enough evidence.

The attention to searching, appraisal and synthesis coupled with a concern about replicability offer transferable benefits to all undertaking any form of review. However, bibliographic databases present many challenges to the researcher, especially in the field of social care where we rely on multiple databases. This coupled with the breadth of unpublished social work research, requires an exacting search technique to ensure coverage is exhaustive although 'perfect searching' is not possible (Clapton, 2 010). The emphasis on transparency, rigour and comprehensiveness encourages further debate about what evidence and knowledge we currently prioritize in social work knowledge production. Social work researchers in the UK need to be more open to the benefits of systematic reviews and see their potential for revealing what is known in a specific area of practice at a specific time and place. These aims naturally align themselves with social work's ethical basis and our code of research conduct (Butler, 2003). 


\section{References}

BASW (2011) The Code of Ethics for Social Work, statement of principles. Accessed on 14.06.12 at http://cdn.basw.co.uk/upload/basw_112315-7.pdf

Boaz, A., Ashby, D. and Young, K. (2002) Systematic Reviews: What have they got to offer evidence based policy and practice? Working Paper2., London: ESRC UK Centre for Evidence Based Policy and Practice

Braye, S., and Preston-Shoot, M (2005) Emerging from out of the shadows? Service user and carer involvement in systematic reviews. Evidence \& Policy, 1, 2, 173-194

Braye, S., and Preston-Shoot, M. (2007) On systematic reviews in social work: observations from teaching, learning and assessment of law in social work education. British Journal of Social Work, 37, 313-334

Butler, I. (2002) A code of ethics for social work and social care practice; A critical commentary. British Journal of Social Work 32, 2, 239-248

Campbell Collaboration (2011) What is a Systematic Review? Accessed on 14.06.12 at http:// www.campbellcollaboration.org/what_is_a_systematic_review/index.php

Clapton, J. (2010) Bibliographic Databases for Social Care Searching. London: SCIE

Coren, E and Fisher, M. (2006) The Conduct of Systematic Research Reviews for SCIE. London: SCIE

Grayson, L., and Gomersall, A. (2003) A Difficult Business: finding the evidence for social science reviews, Working Paper 19. London: ESRC UK Centre for Evidence Based Policy and Practice

Grant, M., and Booth, A. (2009) A typology of reviews: An analysis of 14 review types and associated methodologies. Health Information and Libraries Journal 26, 2, 91-108

Greenhalgh, T., and Peacock, R. (2005) Effectiveness and efficiency of search methods in systematic reviews of complex evidence: Audit of primary sources. British Medical Journal 331, 1064-1065

Hart, C. (2001) Doing a Literature Search: A comprehensive guide for the social sciences. London: Sage

Higgins, J. and Green, S. (2011) Cochrane Handbook for Systematic Reviews of Interventions. Accessed on 30.01.2012 at http://www.cochrane-handbook.org/

Hodge, D., Lacasse, J., and Benson, O. (2011) Influential publications in social work discourse: The 100 most highly cited articles in disciplinary journals: 2000-09. British Journal of Social Work, advance access. Accessed 31.01.12 at http://bjsw.oxfordjournals.org/content/ early/2011/07/07/bjsw.bcr093.short?rss=1

Holden, G., Barker, K., Covert-Vail, L., Rosenberg, G., and Cohen, S.A (2007) Does Social Work Abstracts work? Research on Social Work Practice 18, 5, 487-499

Holden, G., Barker, K., Covert-Vail, L., Rosenberg, G. and Cohen, S.A. (2009) Social Work Abstracts fails agains; A replication and extension. Research on Social Work Practice 19, 6, 715-721

Humphries, B. (2008) Social Work Research for Social Justice. Basingstoke: Palgrave Macmillan Littel, J (2010) Cochrane and Campbell Review Methods: What do we share? How do we differ? Paper at The Colorado Colloquim in 2010. Accessed on 14.06.12 at http://www.cochrane.org/ 
multimedia/multimedia-cochrane-colloquia-and-meetings/colloquium-colorado-2010/ plenary-1-julia-littel

Mackay, G. (2007) Is there a need to differentiate between qualitative and quantitative searching strategies for literature reviewing? Qualitative Social Work 6, 2, 231-241

McDonald, G. (2003) Using systematic Reviews to Improve Social Care. London: SCIE

Marsh, P., and Fisher, M. (2005) Developing the Evidence Base for Social Work and Social Care Practice. London: SCIE

Mitchell, F., Lunt, N. and Shaw I. (2010) Practitioner research in social work: A knowledge review. In Evidence and Policy 6, 1, 7-31

Norton, M. (2008) Systematic reviews: can qualitative social work research live up to the zeitgeist? In Qualitative Social Work 7, 3, pp. 381-386

Orme, J., and Powell, J. (2007) Building research capacity in social work: process and issues. In British Journal of Social Work 38, 5, 988-1008

Pawson, R. (2002) Does Megan's Law Work? A Theory-Driven Systematic Review. Working Paper 8. London: ESRC UK Centre for Evidence Based Policy and Practice

Pawson, R., Boaz, A., Grayson, L., Long, A. and Barnes, C. (2003) Knowledge Review Three:Types and Quality of Knowledge in Social Care. London, SCIE

Rutter, D., (2009) Practice Enquiry Guidelines: A framework for SCIE commissioners and providers. London: SCIE

Rutter, D., Francis, J., Coren, E and Fisher, M. (2011) SCIE systematic Research Reviews: Guidelines (2 ${ }^{\text {nd }}$ ed.) London: SCIE

Spencer, L Ritchie, J., Lewis, J., and Dillon, L. (2003) Quality in Qualitative Evaluation: A framework for assessing research evidence. London: The Cabinet Office

Taylor, B., Demspter, M., and Donnelly, M. (2003) Hidden Gems; systematically searching electronic databases for research publications for social work and social care. In British Journal of Social Work 33, , 4, 423-439

Taylor, B., Wylie, E., Demspter, M., and Donnelly, M. (2007) Systematically retrieving research: A case study evaluating seven databases. Research on Social Work Practice 17, 6, 697-706

Taylor, B. (2009) Invited commentary on papers by Holden et al. and Shek on the quality of Social Work Abstracts. Research on Social Work Practice 19, 6, 366-369

Walter, I., Nutley, S., Percy-Smith, J., McNeish, D. and Frost, S. (2004) Improving the Use Of Research In Social Care Practice. SCIE Knowledge review 07. London: SCIE

Woods,K., Bond, C., Humphrey, W., Symes, N., and Green, L. (2011) Systematic Review of Solution Focuused Brief Therapy with Children and Families. London: DoE

Younger, P., and Boddy, K (2008) When is a search not a search? A comparison of searching the AMED complementary health database via EBSCOhost, OVID and DIALOG. In Health Information and Libraries Journal 26, pp.126-135 